\title{
Wild boar tuberculosis in Iberian Atlantic Spain: a different picture from Mediterranean habitats
}

\author{
Marta Muñoz-Mendoza', Nelson Marreros², Mariana Boadella², Christian Gortázar², Santiago Menéndez ${ }^{3}$, \\ Lucía de Juan ${ }^{4,5}$, Javier Bezos ${ }^{4}$, Beatriz Romero ${ }^{4}$, María Francisca Copano ${ }^{6}$, Javier Amado ${ }^{6}$, José Luis Sáez \\ Jorge Mourelo ${ }^{1}$ and Ana Balseiro ${ }^{8^{*}}$
}

\begin{abstract}
Background: Infections with Mycobacterium bovis and closely related members of the Mycobacterium tuberculosis complex (MTC) are shared between livestock, wildlife and sporadically human beings. Wildlife reservoirs exist worldwide and can interfere with bovine tuberculosis (TB) eradication efforts. The Eurasian wild boar (Sus scrofa) is a MTC maintenance host in Mediterranean Iberia (Spain and Portugal). However, few systematic studies in wild boar have been carried out in Atlantic regions. We describe the prevalence, distribution, pathology and epidemiology of MTC and other mycobacteria from wild boar in Atlantic Spain. A total of 2,067 wild boar were sampled between 2008 and 2012.
\end{abstract}

Results: The results provide insight into the current status of wild boar as MTC and Mycobacterium avium complex (MAC) hosts in temperate regions of continental Europe. The main findings were a low TB prevalence (2.6\%), a low proportion of MTC infected wild boar displaying generalized TB lesions (16.7\%), and a higher proportion of MAC infections (4.5\%). Molecular typing revealed epidemiological links between wild boar and domestic - cattle, sheep and goat - and other wildlife - Eurasian badger (Meles meles) and red fox (Vulpes vulpes) - hosts.

Conclusions: This study shows that the likelihood of MTC excretion by wild boar in Atlantic habitats is much lower than in Mediterranean areas. However, wild boar provide a good indicator of MTC circulation and, given the current re-emergence of animal TB, similar large-scale surveys would be advisable in other Atlantic regions of continental Europe.

Keywords: Wild boar, Tuberculosis, Mycobacterial infections, Atlantic Spain, Cattle

\section{Background}

Bovine tuberculosis (TB) is caused by infection with Mycobacterium bovis and closely related members of the Mycobacterium tuberculosis complex (MTC) [1]. These infections are shared between livestock, wildlife and sporadically, human beings. This re-emerging zoonotic disease is receiving increased attention from scientists and government agencies. Wildlife reservoirs exist worldwide and can interfere with cattle TB eradication efforts $[2,3]$. There are three significant wildlife MTC maintenance hosts in Europe, namely the Eurasian badger (Meles meles), mainly in the United Kingdom

\footnotetext{
* Correspondence: abalseiro@serida.org

${ }^{8}$ SERIDA, Servicio Regional de Investigación y Desarrollo Agroalimentario,

Centro de Biotecnología Animal, 33394 Deva-Gijón, Asturias, Spain

Full list of author information is available at the end of the article
}

(UK) and Republic of Ireland (RoI), the Eurasian wild boar (Sus scrofa), mainly in Mediterranean Spain and Portugal, and deer belonging to the subfamily Cervinae such as the red deer (Cervus elaphus) in several regions throughout Europe [4].

Based on habitat, climate features and wildlife population characteristics, Spain can be divided into six bioregions (BR) [5]; the humid and temperate Atlantic Spain would be represented by BR1, including Galicia and Asturias among other regions, along the north coast of the Iberian Peninsula (Figure 1). Continental Mediterranean habitats would be represented by BR3. In Spain, TB in cattle declined significantly from a herd prevalence of $2.24 \%$ in 2002 to $1.33 \%$ in 2011 [6]. However, the distribution of positive cattle herds in Spain, based on positive single tuberculin skin test confirmed by culture, is not uniform, with higher prevalence 


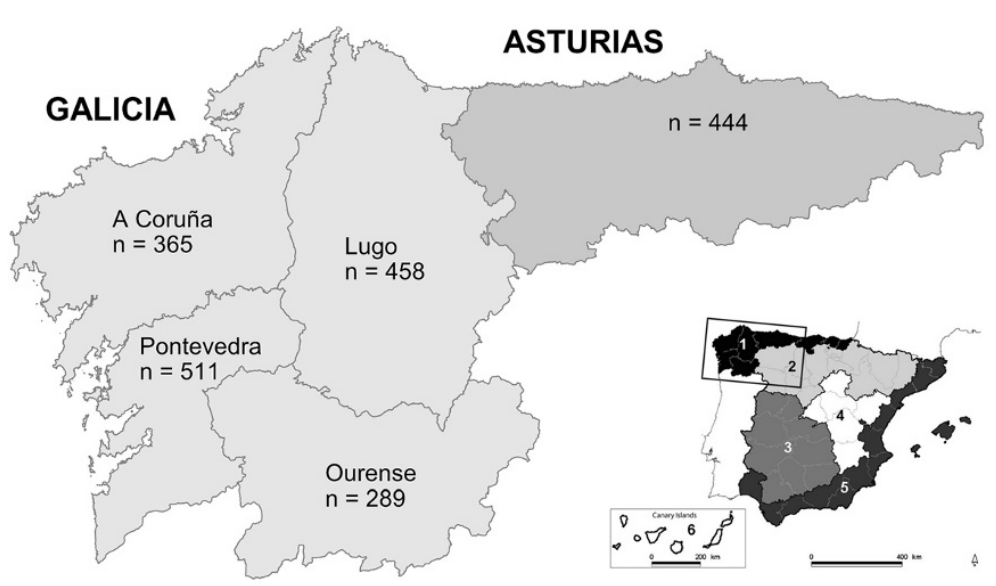

Figure 1 Bioregions (BR) in Spain and number of wild boar sampled in BR1. On the right: map of Spain divided into six large BR for sampling and wildlife disease monitoring. Magnified region: number ( $n$ ) of wild boar sampled in Atlantic Spain (Asturias and Galicia). Both communities belong to the Atlantic BR1 of Spain.

(up to 6\%) in Mediterranean habitats of the south and west of the Spanish mainland and low $(<1 \%)$ prevalence elsewhere (Table 1) [6]. In 2011 Asturias and Galicia reported cattle herd prevalences of 0.14 and $0.19 \%$, respectively. However, both regions included hotspots (Local Veterinary Units) where cattle herd prevalence was $>4 \%$.

Wildlife monitoring is needed to identify changes in disease occurrence and to measure the impact of interventions [7,8]. Wildlife Disease Surveillance Schemes have provided the tools for wildlife disease monitoring. These schemes have been in place in Atlantic Spain in Asturias and Galicia since 2001 and 2008, respectively, and have been pivotal for instance for assessing the TB situation of badgers in this region. The recent increase in awareness of TB in wildlife prompted surveillance of badgers in several regions and countries with suitable badger habitats in continental Europe, including Atlantic Spain. Research has estimated prevalence of $M$. bovis infection to be $12.4 \%$ in badgers in northern Spain, with spatial correlation of isolates from cattle and badgers $[9,10]$.

One recommendation for monitoring diseases in wildlife is selecting the most appropriate wildlife hosts [8]. Wild boar are considered the best TB surveillance target because of their wide habitat range, high abundance and easy accessibility for sampling as a game species. Moreover, wild boar are easy to test for TB because of their lesion distribution $[11,12]$ and the availability of specific and sensitive antibody tests [13]. MTC infection has been diagnosed in about $50 \%$ of wild boar from South-Western Spain [12,14], and in $11.11 \%$ of wild boar from Portugal [15]. Outside the Iberian Peninsula, wild boar TB has been reported from eight European countries [4], including one local survey with a prevalence of $42 \%$ in Normandy (France) [16], and prevalences of 3\% in northern Italy [17], and 3.6\% in Switzerland and Liechtenstein [18]. This demonstrates an increasing importance of this ungulate regarding TB in Europe. However, no systematic studies in wild boar have been carried out in Atlantic Spain, although a seroprevalence between $0.01-5 \%$ was established in a recent cross-sectional serosurvey [19], confirming the wild boar as a sensitive host to MTC infection.

There are few reports of Mycobacterium avium complex (MAC) spp. infections in wild boar. M. avium subsp. hominissuis was isolated from two wild boar in Portugal [20] and $M$. avium subsp. avium from three and four wild boar in Italy and Spain, respectively [21,22]. A recent study has reported a $M$. avium prevalence of $11 \%$ by culture in Southern Spain [23]. MAC infections in wild boar are of

Table 1 Prevalence of tuberculosis (TB) by single tuberculin skin test and culture in cattle herds in different regions in Mediterranean (BR3, Figure 1) and Atlantic Spain (BR1, Figure 1) from 2008 to 2011 [6]

\begin{tabular}{|c|c|c|c|c|c|}
\hline \multirow[b]{2}{*}{ Year } & \multicolumn{3}{|c|}{ BR3, representative of Mediterranean Spain } & \multicolumn{2}{|c|}{ BR1, Atlantic Spain } \\
\hline & Andalucía (\%) & Castilla la Mancha (\%) & Extremadura (\%) & Galicia (\%) & Asturias (\%) \\
\hline 2008 & 5.80 & 11.62 & 3.37 & 0.11 & 0.22 \\
\hline 2009 & 8.94 & 10.27 & 3.78 & 0.22 & 0.21 \\
\hline 2010 & 8.54 & 7.11 & 3.04 & 0.28 & 0.18 \\
\hline 2011 & 6.16 & 5.35 & 3.11 & 0.19 & 0.14 \\
\hline
\end{tabular}

BR3 is characterized by much higher incidence of TB in cattle herds than BR1. 
potential relevance due to the possible diagnostic interference with MTC infections by serology or pathology, particularly if culture and identification by polymerase chain reaction (PCR) is not performed.

The aims of the present study were (1) to document the MTC and MAC situation in wildlife of Atlantic Spain, with a focus on wild boar (considered a good target species) using serological, bacteriological, molecular and pathological diagnostic techniques, (2) to identify associations between infected wild boar populations, infected cattle and other infected domestic and wildlife species, and (3) to establish epidemiological and spatial links between MTC strains from domestic animals and wildlife in a particular region.

\section{Methods}

\section{Ethics statement}

All samples were taken from legally hunted wild boar. Sampling procedures were approved by the Animal Research Ethics Committee of SERIDA (reference numbers 041/06-01-2008 and 010/07-01-2011). We also had the permission to use the samples from the goverment (Sección de Caza de la Consejería de Medio Ambiente del Principado de Asturias and Consejería de Medio Rural y de Mar de la Xunta de Galicia). Animals were hunted and no animals were killed specifically for this study. All data from domestic animals derive from the official testing schemes and did not require animal experiment ethics approval.

\section{Study area}

Free-ranging wild boar from Asturias and Galicia (4.5E to $9.3 \mathrm{~W}$ and $41.8 \mathrm{~N}$ to $43.8 \mathrm{~N}$ ) were studied (Figure 1). In these regions, wild boar are harvested through largely non-commercial hunting, and neither large scale fencing nor artificial feeding exists.

Both regions belong to the Atlantic bioregion of Spain (BR1) [5]. BR1 is characterized by an Atlantic climate with a high average precipitation of $>1000 \mathrm{~mm} /$ year and mild winter average temperature. Main geographical features are the Atlantic coast to the north and west and the Cantabrian Mountains to the south. Cattle farming (>73,000 herds), both dairy and beef, is a significant activity in both regions. Culture and molecular typing data were available for cattle culled as part of the National Program for the Eradication of TB between 2008 and 2012 in both regions [24], and also for sheep, goat, badger, roe deer (Capreolus capreolus) and fox (Vulpes vulpes) (Table 2) [10,24].

\section{Wild boar studied}

A total of 2,067 wild boar were sampled between 2008 and 2012 (Table 3): 1,623 originated from Galicia (divided into four provinces) and 444 from Asturias (one province). Thus, the sampled wild boar originated from five provinces
Table 2 Number of domestic and wildlife species subjected to culture in Galicia and Asturias between 2008-2012 and prevalence of $M$. tuberculosis complex (MTC) and Mycobacterium avium complex (MAC) mycobacteria $[6,9,24]$

\begin{tabular}{|c|c|c|c|c|c|c|}
\hline & \multicolumn{3}{|c|}{ Domestic animals } & \multicolumn{3}{|c|}{ Wildlife species } \\
\hline & Cattle* & Sheep ${ }^{* *}$ & Goat** & Badger & $\begin{array}{l}\text { Roe } \\
\text { deer** }\end{array}$ & Fox $^{* *}$ \\
\hline Total cultured & 4,768 & 167 & 109 & 182 & 350 & 107 \\
\hline $\begin{array}{l}\text { MTC-infected } \\
(\%)\end{array}$ & $\begin{array}{l}934 \\
(19.59)\end{array}$ & $\begin{array}{l}82 \\
(49.10)\end{array}$ & $\begin{array}{l}43 \\
(39.45)\end{array}$ & $\begin{array}{l}14 \\
(7.69)\end{array}$ & $\begin{array}{l}0 \\
(0.0)\end{array}$ & $\begin{array}{l}2 \\
(1.87)\end{array}$ \\
\hline $\begin{array}{l}\text { MAC-infected } \\
(\%)\end{array}$ & $\begin{array}{l}48 \\
(1.01)\end{array}$ & $\begin{array}{l}0 \\
(0.0)\end{array}$ & $\begin{array}{l}0 \\
(0.0)\end{array}$ & $\begin{array}{l}16 \\
(8.79)\end{array}$ & $\begin{array}{l}4 \\
(1.43)\end{array}$ & $\begin{array}{l}2 \\
(1.87)\end{array}$ \\
\hline
\end{tabular}

*Cattle subjected to culture were first positive by the single tuberculin skin test during national campaigns of eradication of TB. **Note that sampling of sheep, goat, roe deer and fox was performed mainly in areas with a previous history of TB in cattle.

(Figure 1). Wild boar were harvested by hunters during the legal hunting season (October to February). The number of sampled wild boar per hunting season was heterogeneous; 2007-2008: $n=6,2008-2009: \mathrm{n}=163,2009-2010: \mathrm{n}=300$, 2010-2011: $n=643,2011-2012: \mathrm{n}=916$. No data on hunting season was available for 39 wild boar.

In Galicia, official veterinarians in collaboration with hunters' associations collected blood samples from the heart of the animals, and tissue samples (lungs, tonsils and mandibular, tracheobronchial, mediastinal and mesenteric lymph nodes-LN) were taken, along with sex and age data of each wild boar for further processing. In Asturias, a trained veterinarian sampled blood and tissues (including also retropharyngeal LN) in the field immediately after hunting. The sex ratio was almost balanced with 954 females and 930 males. No data on sex was available for 183 wild boar. Age was determined according to the tooth eruption pattern. There were $n=220$ : $<12$ months, $\mathrm{n}=688:<30$ month and $\mathrm{n}=289$ animals older than 30 months. Age data was not available for 870 wild boar.

\section{Bacteriological studies}

The Mycobacteria Growth Indicator Tube (MGIT) liquid medium system, Löwenstein-Jensen solid media with sodium pyruvate and Coletsos solid media [25,26] were used to isolate members of the MTC and M. avium complex (MAC) in samples from 1,275 wild boar sampled from

Table 3 Number of samples from wild boar analyzed and diagnostic technique performed in each region of Atlantic Spain between 2008 and 2012

\begin{tabular}{lllll}
\hline Regions & \multicolumn{4}{c}{ Technique } \\
\cline { 2 - 5 } BR1 & Culture & ELISA & Culture/ELISA & Culture/histology \\
\hline Galicia & 831 & 613 & 265 & - \\
Asturias & 444 & 444 & - & 70 \\
Total & 1,275 & 1,057 & 265 & 70 \\
\hline
\end{tabular}


areas with history and/or high prevalence of TB in cattle (Table 3). Specific media to isolate M. avium subsp. paratuberculosis were not used in this study. Pools of tissues ( $2 \mathrm{~g}$ ) from the lungs, tonsils and mandibular, tracheobronchial, mediastinal and mesenteric LN (in Galicia) or from the lungs and the retropharyngeal, mandibular, tracheobronchial and mediastinal LN (in Asturias) of each wild boar were decontaminated using the BBL MycoPrep Becton Dickinson kit (BD Diagnostic Systems, USA). MGIT liquid medium was incubated at $37^{\circ} \mathrm{C}$ for at least 6 weeks using the automated BACTEC MGIT 960 (BD Diagnostic Systems, USA). Solid media were incubated at $37^{\circ} \mathrm{C}$ for at least 10 weeks.

\section{Identification and molecular characterization of isolates}

Real Time-Polymerase Chain Reaction (qPCR) to identify MTC species was performed on culture isolates using the MTC forward primer 5'-TAGTGCATGCACC GAATTAGAACGT-3', the MTC reverse primer 5'-CGA GTAGGTCATGGCTCCTCC-3' and the TaqMan probe YY/BHQ 5'-AATCGCGTCGCCGGGAGC-3', which amplifies a 184 base pair fragment [27]. RT-PCR amplification involved an initial denaturation cycle at $95^{\circ} \mathrm{C}$ for $10 \mathrm{~min}$, followed by 40 cycles of denaturation, annealing and extension at $95^{\circ} \mathrm{C}$ for $30 \mathrm{~s}$ and $60^{\circ} \mathrm{C}$ for $1 \mathrm{~min}$.

MTC isolates were characterized by DVR-spoligotyping [28] following hybridisation of biotin-labelled PCR products onto a spoligotyping membrane (Isogen Bioscience BV and VISAVET 'home-made' membrane). Results were recorded in SB code followed by a field of four digits according to the M. bovis Spoligotype Database website [29]. The MTC isolates were compared with those identified in cattle and badger (when available) from the same area [10,24]. To confirm the similarity of isolates from cattle, wild boar and other domestic and wildlife species from the same geographical location, Mycobacterial Interspersed Repetitive Units - Variable Number Tandem Repeats (MIRU-VNTR) typing was performed [30] using four (ETR-A, ETR-B, QUB11a, QUB3232) or nine (ETR-A, ETR-B, ETR-D, ETRE, MIRU26, QUB11a, QUB11b, QUB26 and QUB3232) VNTR markers.

Identification of MAC species was performed on positive cultures [31], using the MAC forward primer 5'-AACGTGTTCTACCTCTGCGGGGCAAG-3' (nucleotides 34-59 in the sequence GenBank X68102), the MAC reverse primer 5'-CCGGGAGAGTAGGTCATGGCTCC-3' (nucleotides 259-281 in the sequence GenBank X68102) and the TaqMac Cy5/BHQ 5'-CGCTCGGCACTAAAAGGCAGT GG-3' (nucleotides 221-240 in the sequence GenBank X68102) (Cultek, Spain), which amplifies a 248 bp fragment. RT-PCR was carried out at $95^{\circ} \mathrm{C}$ for $10 \mathrm{~min}$, followed by 40 cycles of $95^{\circ} \mathrm{C}$ for $30 \mathrm{~s}$ and $60^{\circ} \mathrm{C}$ for $1 \mathrm{~min}$. PCR amplification of IS1245, IS901 and IS901-flanking region
(FR300) genomic targets was carried out as MAC subspecies can be readily differentiated on the basis of their IS1245, IS901 and FR300 genotype. Thus, M. avium subsp. avium is IS1245+, IS901+ and FR300- (a band at 1742 bp is present, but there is no band at $300 \mathrm{bp}$ ), while M. avium subsp. hominissuis is IS1245+, IS901- and FR300+. M. avium subsp. silvaticum is IS1245+, IS901+ and FR300+, and $M$. intracellulare is negative for all three targets.

\section{Serological study}

A recently developed enzyme-linked immunosorbent assay (ELISA) was used to identify seropositive wild boar [13]. This test uses a bovine tuberculin purified protein derivative (bPPD) as coating antigen and protein G horseradish peroxidase as conjugate. The test has a moderate sensitivity (79.2\%) and good specificity (100\%) in detecting MTC infected wild boar. Sera from 1,057 wild boar were tested by ELISA (Table 3), following the protocol described previously [13].

\section{Gross and histopathological examinations}

The TB lesion pattern has been well described previously in wild boar from Mediterranean Spain [11,32]. Macroscopic TB lesions in Mediterranean wild boar were classified as "localized", if only one anatomical region was affected, or "generalized", if at least two different anatomical regions were affected, and were termed " $\mathrm{A}$ " if lesions were less than $10 \mathrm{~mm}$ in diameter and " $\mathrm{B}$ " if they were over $10 \mathrm{~mm}$ diameter. Microscopic lesions were also classified as "granuloma 1", initial granulomas composed of mixed inflammatory cells only or with a necrotic core; "granuloma 2", slightly necrotic-calcified granulomas with scarce calcium deposits in the necrotic core; and "granuloma 3", strongly necrotic-calcified granulomas with a calcification area similar to or bigger than the necrosis area [11]. We used the same classification for wild boar from Atlantic Spain.

Gross lesions observed in 70 wild boar from Asturias were carefully recorded based on Martín-Hernando et al. [11]. Mandibular, retropharyngeal, mediastinal, and tracheobronchial LN (up to $0.5 \mathrm{~cm}$ thickness), and lung and spleen (up to $2 \mathrm{~cm}$ thickness) were sliced for further macroscopic observation. Any other organ showing lesions suggestive of TB was processed in the same way as lungs.

Samples for histopathology were taken from the mandibular, retropharyngeal, tracheobronchial and mediastinal LN, lungs and spleen of 70 Asturian wild boar (Table 3). In one case liver was also collected because of gross lesions. They were fixed in $10 \%$ neutral buffered formalin and processed routinely. Several sections of $4 \mu \mathrm{m}$ were cut from each sample and stained with haematoxylin and eosin (HE) and by Ziehl-Neelsen (ZN) method for acidfast bacteria (AFB). In selected positive cases showing TBlike lesions immunohistochemical examination by means of the peroxidase anti-peroxidase (PAP) method was 
performed [33]. The sections were incubated with specific anti-M. bovis serum (Dako, Denmark), diluted 1 in 2,000. To evaluate the specificity of the anti-M. bovis antibody, tissue samples from a tuberculous cow were used. Normal non-infected rabbit serum (Dako, Denmark) was used as a negative control.

\section{Statistical analysis}

Differences in prevalence between years, sexes, age classes, were assessed with the two tailed Fisher's exact test (FET) for both ELISA and culture results. In case of multiple comparisons, the Bonferroni correction was applied. Significance level was set at $\mathrm{P}<0.05$. Agreement between serology and culture was assessed by Cohen's Kappa coefficient using 265 wild boar which were analyzed by both techniques (Table 3). Statistical analysis of wild boar data was performed with the $R$ statistic software (version 2.14.2) [34] in combination with the "vcd" package (version 1.2-12) [35] for calculation of the Cohen's Kappa coefficient.

\section{Spatial cluster analysis}

Wild boar were identified using the Cartesian coordinates of the centroid of their hunting area of origin. Presence of geographic clusters of TB was assessed with the SaTScan Software (version 9.1.1, www.satscan.org). For this purpose, the Bernoulli model for purely spatial clusters was chosen, which was conducted in an iterative way. Geographic data on hunting areas was obtained from the Consejería de Medio Rural y de Mar de la Xunta de Galicia, and the Consejería de Medio Ambiente del Principado de Asturias. Geographic data visualization and processing was performed with the GvSIG software (version 1.12, www.gvsig.org).

\section{Results}

\section{Culture, identification of isolates and spoligotyping}

MTC species were isolated and identified by RT-PCR from 33/1,275 wild boar (2.59\%; 95\% CI: $1.8-3.6$, Table 4). No significant difference was found between sex, age class or hunting season. The isolates were identified as $M$. bovis $(\mathrm{n}=19)$ or $M$. caprae $(\mathrm{n}=14)$ and were characterised by spoligotyping as SB0157-M. caprae $(\mathrm{n}=14)$, SB0130-M. bovis $(\mathrm{n}=5)$, SB0152-M. bovis $(\mathrm{n}=4)$, SB0140-M. bovis $(\mathrm{n}=4)$, SB0134-M. bovis $(\mathrm{n}=3)$ and SB0121-M. bovis $(\mathrm{n}=3)$ (Figures 2 and 3). MIRU-VNTR analysis of the four loci (ETR-A, ETR-B, QUB11a, and QUB3232) subdivided the isolates typed as SB0157 in 5 MIRU-VNTR types, SB0130 in 3 VNTR types, and SB0140 in 2 VNTR types (Table 5). One SB0121 isolate from wild boar could not be typed by MIRU-VNTR. In order to track the dissemination of the disease we selected at least one isolate from cattle farms $(n=30)$ with the same spoligotyping profile and from the same area and isolates from other animal species [badger $(n=3)$, sheep $(n=1)$, goat $(n=3)$ and fox $(\mathrm{n}=1)$ ] and they were also analysed by VNTR typing.

Relationships between the $M$. bovis/M. caprae isolates from wild boar and the other animal species are shown in Figure 2. The strain SB0157-M. caprae was the most frequently identified in wild boar $(14 / 33,42.42 \%)$ and was only identified once in cattle $(1 / 627,0.16 \%$; odd ratio $=441.5$, FET: $\mathrm{P}<0.001$, Figure 2). The 4 or 9 -loci MIRU-VNTR profile of the wild boar, fox and cattle isolates within the spoligotype SB0121 was the same and minor differences at one locus (MIRU26, QUB11a, or QUB11b) were associated to the SB0130, SB0134, and SB0157 profiles, respectively, although they were considered as belonging to the same clonal complex. However different MIRU-VNTR profiles were found in wild boar and cattle with the SB0152 profile. Similar MIRU-VNTR profiles were associated to wild boar and two caprine flocks with SB0157 profile. Spoligotype SB0140-M. bovis found in wild boar was not identified in cattle or in other species during the study period. VNTR profiling of SB0121 revealed that the strains identified in badgers (5-4-3-3-5-F-2-5-8) and cattle (4-4-3-3-5-10-2-5-8) were different but closely related.

MAC species were isolated from 58/1,275 wild boar (4.55\%; 95\% CI: 3.5-5.8). PCR analysis of the isolates revealed $M$. avium subsp. avium $(\mathrm{n}=15)$ and $M$. avium subsp. hominissuis $(\mathrm{n}=43)$.

\section{Serological results}

Twenty-two out of 1,057 wild boar were positive by ELISA (2.08\%; 95\% CI: 1.3-3.1, Table 4). No significant differences were found between sex, age class or hunting season.

\section{Comparison between culture and ELISA}

Cohen's Kappa coefficient of agreement between MTC positive culture and ELISA was 0.71. We therefore considered

Table 4 Prevalence of $M$. tuberculosis complex (MTC) and $M$. avium complex (MAC) species infection, in wild boar in Atlantic Spain, using culture, serology and pathology

\begin{tabular}{|c|c|c|c|c|c|c|c|}
\hline & \multirow{2}{*}{$\begin{array}{l}\text { Culture } \\
\text { of MTC }\end{array}$} & \multirow{2}{*}{$\begin{array}{l}\text { Culture } \\
\text { of MAC }\end{array}$} & \multirow[t]{2}{*}{ ELISA $M$. bovis } & \multicolumn{4}{|c|}{ Pathology M. bovis } \\
\hline & & & & Gross lesions & Generalized lesions & Localized lesions & $\begin{array}{l}\text { Microscopic lesions } \\
\text { and } \mathrm{IHC}^{*} \text { for } M \text {. bovis }\end{array}$ \\
\hline \multirow[t]{2}{*}{ Wild boar } & $33 / 1,275$ & $58 / 1,275$ & $22 / 1,057$ & $6 / 70$ & $1 / 6$ & $5 / 6$ & $9 / 70$ \\
\hline & $(2.59 \%)$ & $(4.55 \%)$ & $(2.08 \%)$ & $(8.57 \%)$ & $(16.7 \%)$ & $(83.43 \%)$ & $(12.86 \%)$ \\
\hline
\end{tabular}

* IHC Immunohistochemistry was performed on animals with microscopic tuberculosis-like lesions. 


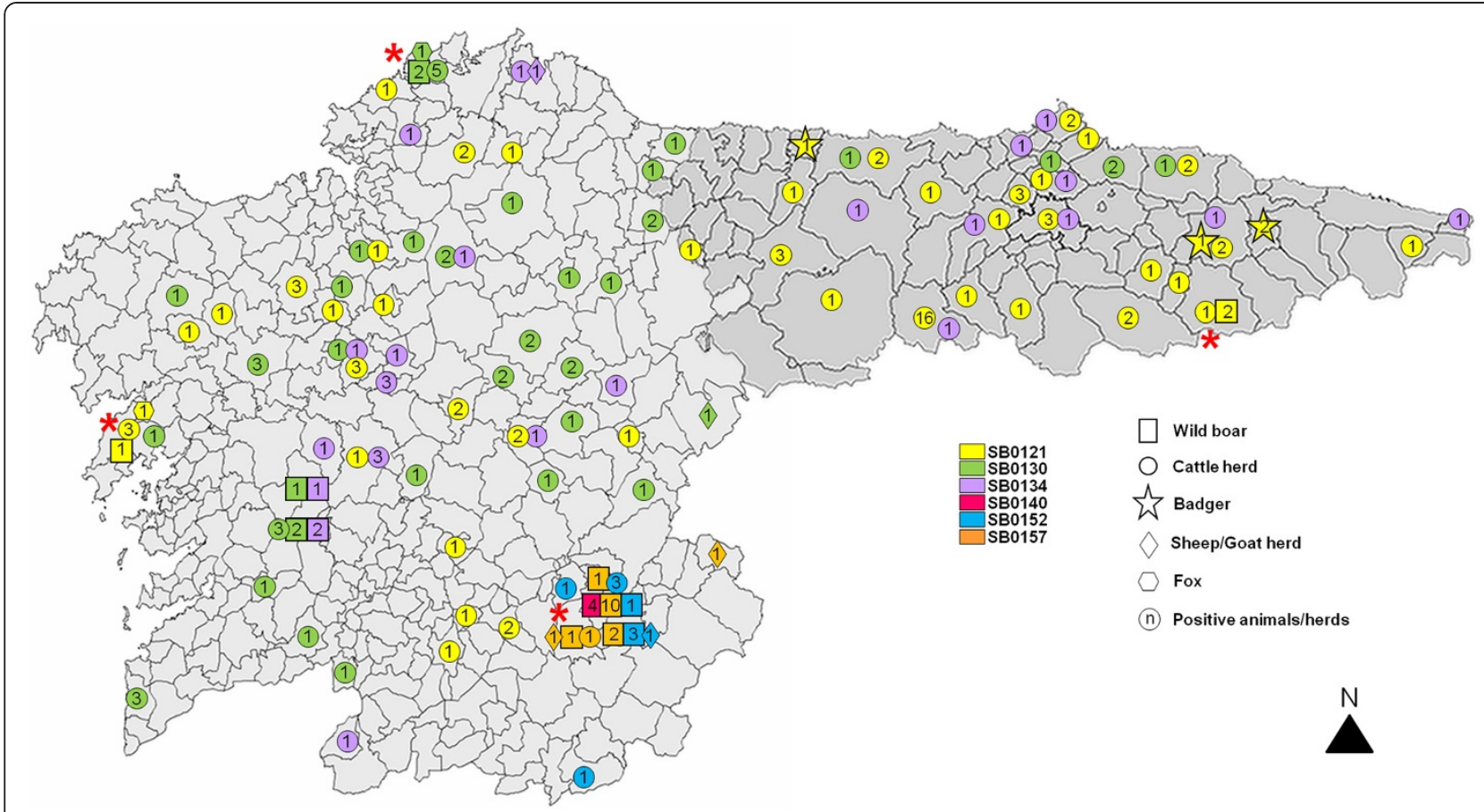

Figure 2 Tuberculosis-positive domestic and wildlife species in Atlantic Spain. Shared Mycobacterium bovis spoligotypes identified in wild boar and other species from 2008 to 2012 are shown. Red asterisks indicate that isolates from domestic and wildlife species share spoligotype profiles in the same geographical areas.

the agreement as fairly good and thus considered pooling the samples for general statistics as appropriate.

\section{Overall statistic and spatial cluster analysis}

Forty-six wild boar were positive by culture or ELISA (2.22\%; 95\% CI: 1.6- 3.0). Spatial cluster analysis revealed 3 significant clusters (A, B and C; relative risk 7.87, 5.98, 10.71; $\mathrm{P}<0.001,0.019,0.013$, respectively; Figure 3). Three spoligotypes were found in cluster A (SB0157-M. caprae, SB0152-M. bovis and SB0140-M. bovis), which were only found in this cluster (Figure 3). Three other spoligotypes were found in cluster $C$, one of which was only found in this cluster (SB0134-M. bovis). SB0121-M. bovis was the only spoligotype found in cluster B.

\section{Pathological investigations}

Gross TB-like lesions were observed in 6 wild boar (6/70, 8.57\%; 95\% CI: 3.2-17.7) from Asturias (Table 4), 5 showing "A" (small) lesions $(5 / 6,83.3 \%$ ) and only one "B" (large) lesions $(1 / 6,16.7 \%)$ (Figure 4a). Five animals had lesions confined to one anatomical region; four of them in the mandibular LN (Figure $4 \mathrm{~b}$ ) and one in the liver. Only one animal (the one with "B" lesions) presented generalized TBlesions located in the head, thorax and abdomen. SB0121$M$. bovis was isolated from this wild boar.
Histopathology allowed us to confirm the presence of TB lesions in a total of $9(9 / 70,12.85 \%)$ wild boar from Asturias, three of them with no visible gross lesions but with typical features of bovine tuberculous granulomas in lungs. Granulomas were classified as Type 1 in three wild boar, Type 2 in three and Type 3 in another three wild boar (Figure 4c). MTC was confirmed by immunohistochemistry. A multifocal intense positive immunolabel was observed in the necrotic areas and in macrophages within and around the granulomas (Figure 4d). AFB were demonstrated with ZN staining in 5/9 cases. Two of these wild boar were positive by culture.

Wild boar infected with MAC showed histopathological lesions indistinguishable from those caused by MTC. However, immunohistochemistry carried out on these animals using the anti- $M$. bovis antibody was negative. Additionally 9 (9/70, 12.85\%) wild boar showing gross lesions initially compatible with $\mathrm{TB}$ in the mandibular LN, were diagnosed as having actinomycosis based on histopathological morphology.

\section{Discussion}

This is the first cross-sectional survey of wild boar TB in Atlantic habitats combining culture, pathology and serology. The results provide insight into the current status of wild boar as MTC hosts in temperate regions of continental 


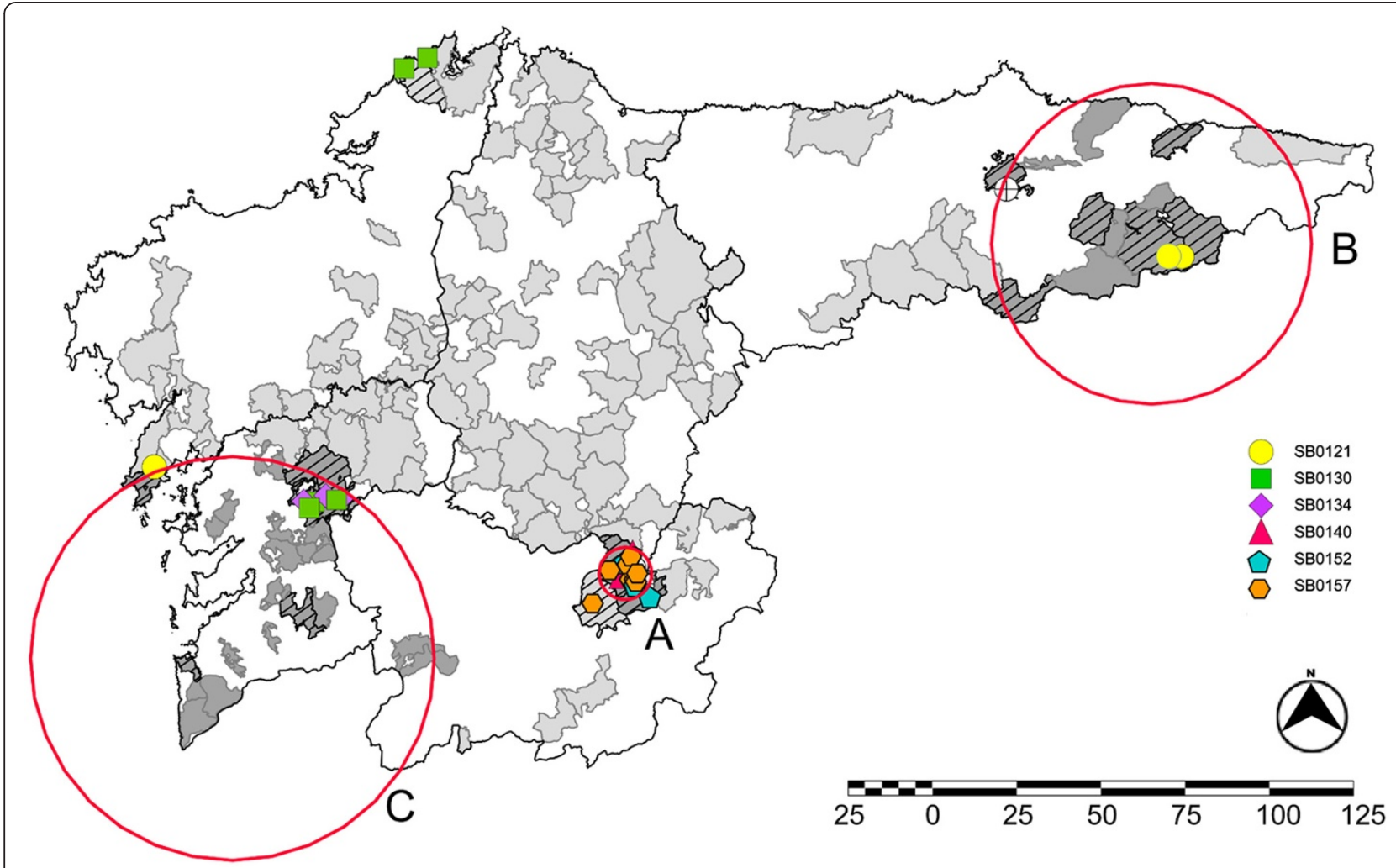

Figure 3 Tuberculosis-positive wild boar in Atlantic Spain and the Mycobacterium bovis spoligotypes identified. Shaded areas represent hunting areas where wild boars were sampled. Striped areas represent hunting areas where at least one wild boar was found positive for TB. Dark shaded areas represent hunting areas included in the cluster with higher risk of TB. Different forms represent the spoligotypes identified. Spatial cluster analysis revealed 3 significant clusters (A, B and $\mathbf{C}$; relative risk 7.87, 5.98, 10.71; P $<0.001,0.019,0.013$, respectively).

Table 5 Identification and genotyping of the Mycobacterium tuberculosis complex isolates $(n=33)$ from wild boar in Atlantic Spain

\begin{tabular}{lll}
\hline Identification & $\begin{array}{l}\text { Spoligotyping profile } \\
\text { (N isolates) }\end{array}$ & $\begin{array}{l}\text { MIRU-VNTR types } \\
\text { (N isolates) }^{* *}\end{array}$ \\
\hline M. caprae & SB0157 (14) & $5-3-6-8(9)$ \\
& $4-3-6-8(2)$ \\
& $5-3-6-7(1)$ \\
& $1-3-6-8(1)$ \\
M. bovis & $6-3-10-10(1)$ \\
& & $4-4-10-8(2)$ \\
& SB0121 (3 $\left.{ }^{*}\right)$ & $4-5-10-9(1)$ \\
& & $4-5-10-10(2)$ \\
& & $4-5-9-8(2)$ \\
& & $3-5-10-5(3)$ \\
& & $6-3-10-10(2)$ \\
& & $6-3-F-F(1)$ \\
& & $4-5-6-8(1)$ \\
& & $7-5-8-7(4)$ \\
\hline
\end{tabular}

${ }^{*}$ DNA from an SB0121 isolate was not available.

*** The order of the MIRU-VNTR loci is ETR-A, ETR-B, QUB11a, and QUB3232. Bold MIRU-VNTR profiles are the most frequent profiles. F. Failure of amplification.
Europe. The main findings were a low TB prevalence, a low proportion of MTC infected wild boar displaying generalized TB lesions, and a higher proportion of MAC infections.

This study provides much needed information on the TB status of wild boar in Atlantic Spain, confirming the presence of mycobacterial infections in these animal populations. The prevalence of MTC infections based on culture $(2.59 \%)$ and serology $(2.08 \%)$ was low. This is in agreement with the low prevalence of seropositive wild boar recorded in Atlantic habitats in a previous nationwide survey $(<5 \%)$ [19]. In contrast, a 52\% MTC infection prevalence using culture was recorded in Doñana National Park in south-western Spain [2], and high infection prevalences have repeatedly been recorded in other regions of Mediterranean Spain and Portugal $[4,36]$. The prevalence of antibodies against MTC was estimated at 35\% in Mediterranean Spain (BR3) [19]. This large difference between the high prevalence in wild boar from Mediterranean regions and the low prevalence in those from Atlantic ones might be due to differences in the presence of several, not mutually exclusive risk factors for MTC infection in wildlife. First, in Atlantic Spain, the prevalence of TB in cattle herds is 

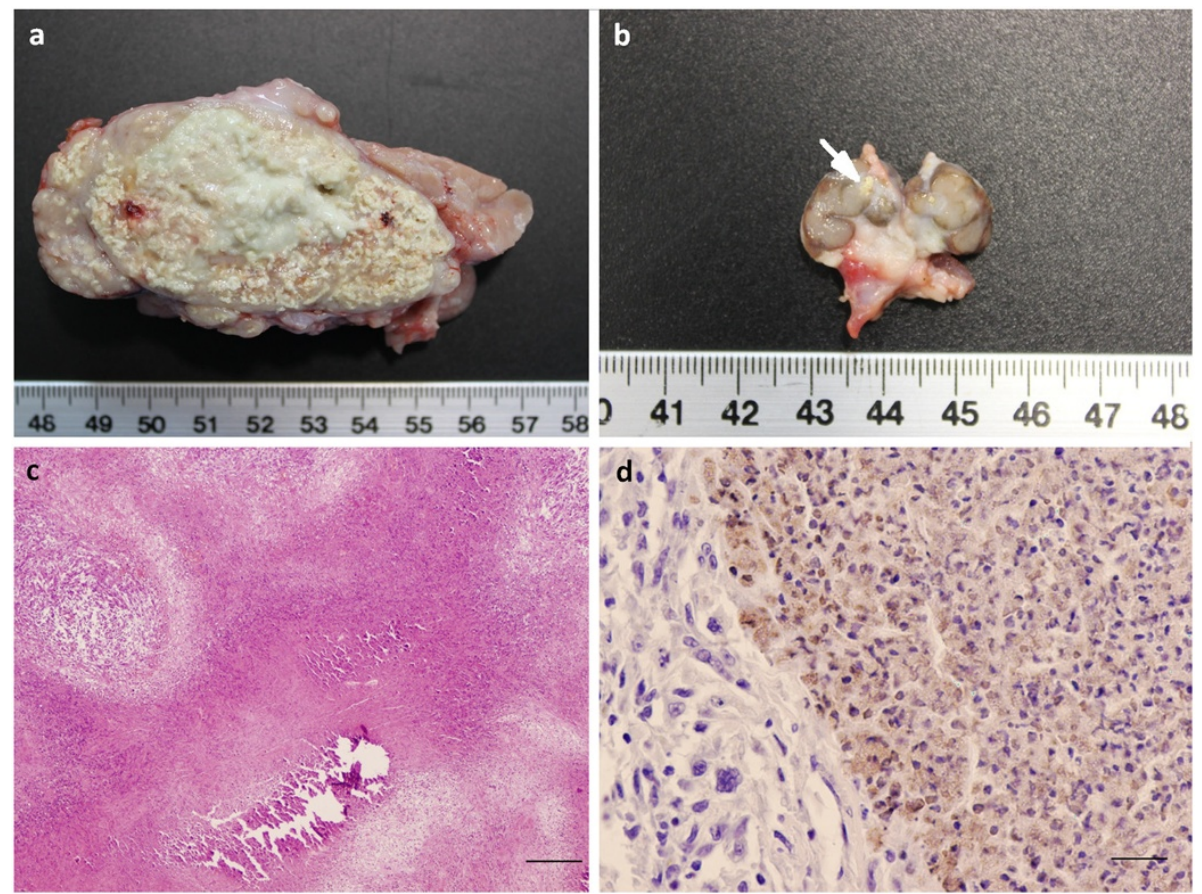

Figure 4 Tuberculous lesions in wild boar from Asturias. a) Severely enlarged mandibular lymph node from a wild boar showing generalized tuberculosis. b) Typical lesion found in mandibular lymph node in wild boar in northern Spain, consisting of small area of calcified necrosis (arrow) confined to one anatomical region. c) Histological section of a mandibular lymph node. Granuloma "type 2" consisted of necrotic-calcified granulomas, with few calcium deposits in the necrotic core. Haematoxylin-eosin staining, bar = $200 \mu \mathrm{m}$. d) Liver. Positive immunostaining for Mycobacterium bovis located in macrophages in the necrotic area. PAP staining, bar $=20 \mu \mathrm{m}$.

very low contrary to the high prevalence of TB in cattle in Mediterranean Spain (Table 1) [6]. Second, wild boar occur at higher densities in Mediterranean habitats than in Atlantic ones in Spain [37,38]. Third, artificial management of wild boar for hunting purposes, including fencing and feeding, is much more common in Mediterranean habitats $[14,39]$. Fourth, dry habitats in Mediterranean Spain facilitate aggregation of animals when watering or feeding (especially during the summer), enabling the transmission of the disease. Such spatial aggregation and intra- or interspecific contacts at waterholes or feeders are less likely to occur in humid Atlantic habitats.

The proportion of lesions found in Atlantic Spain was markedly lower than in Mediterranean habitats. There may be different explanations for the low proportion of individuals with generalized disease observed in the present study (16.7\%). The small sample size available for pathological study could be one of these reasons. This proportion contrasts with the much higher proportion found in Mediterranean Spain (57.8\%) [11]. Interestingly, a recent study has demonstrated how the proportion of severe/ generalized cases of TB among wild boar increases in dry years in southern Spain, although infection prevalence did not increase [Vicente J, unpublished observations]. This was probably a result of higher food restriction and $\mathrm{TB}$ susceptibility, or of augmented aggregation at waterholes.
In our study, the prevalence of confirmed TB gross lesions was also low (8.57\%) as compared to Mediterranean Spain $(82.68 \%)$. Lesions were mainly restricted to small size ones in a single organ -the mandibular LN. Thus, it seems that the likelihood of MTC excretion by wild boar in Atlantic Spain is much lower than in Mediterranean habitats, and that most of the infected animals would shed small amounts of bacteria, if any.

Prevalence of histopathological lesions in Asturias was higher $(9 / 70,12.85 \%)$ than prevalence obtained by using culture $(2 / 70,2.86 \%)$. The histopathological findings suggest that an exhaustive pathological study of tissues increases prevalence and that we may have missed infected wild boar by only using culture. The gold standard for TB diagnosis is post-mortem examination with bacteriological confirmation [2]. The number of tissues examined and their pooling may have impaired the sensitivity of culture in this study. However, the average small size of the lesions found in Atlantic Spain has also to be taken into account since it may impair the isolation of mycobacteria. Sampling additional tissues would have increased the sensitivity, as shown for badgers [40].

In this study ELISA results showed a good agreement with culture and this assay has been a pivotal tool for the diagnosis and cost-effective large scale monitoring of $\mathrm{TB}$ in this area. Wild boar blood can be easily and cleanly 
collected [41], and ELISA has proven to be a useful first screening tool. Moreover, ELISA can also be used for detecting areas at risk for targeted surveys based on more sensitive techniques. If this approach is proposed in other Atlantic areas where wild boar TB is understudied, the bigger picture of the epidemiology in the wild boar TB could be revealed.

Wildlife and cattle in the same areas frequently share the same MTC strains [10,14,42]. The most frequent spoligotype found in cattle and badger in Spain was SB0121-M. bovis [10]. However, in this study the most frequent spoligotype in wild boar was SB0157-M. caprae (42.42\%) and SB0121 was the least frequent. We identified six different $M$. bovis/M. caprae spoligotypes, four of which (SB0121-M. bovis, SB0130-M. bovis, SB0134-M. bovis and SB0157-M. caprae) had previously been identified in cattle, two (SB0152-M. bovis and SB0157-M. caprae) in goat and sheep and two (SB0121-M. bovis and SB0130-M. bovis) in fox. VNTR analysis contributed with additional information about the strains and demonstrated that cattle isolates with the SB0121, SB0130, SB0134, and SB0157 profiles were geographically associated with wild boar, suggesting an epidemiological link between these species. By contrast VNTR study of the isolates from the wild animal species and cattle with the SB0152-M. bovis did not find any link. The finding of a strain pattern in wild boar (SB0140-M. bovis) that was neither detected in cattle nor in other species during the study period would suggest some cases of independent MTC circulation among wild boar. This was not seen in badgers in previous studies [10]. Also, the identification of SB0157-M. caprae strain in wild boar (42.42\%) more frequently than in cattle $(0.16 \%)$ suggests some differences between the wild and domestic cycles of MTC epidemiology in this study area. However, it must be taken into account that SB0157-M. caprae was identified in one single "hot-spot" area where cattle, goats and sheep also shared this strain.

MAC species (M. avium subsp. avium and M. avium subsp. hominissuis) were identified in wild boar at similar prevalences than MTC species, as also happened with sympatric badgers [9]. This indicates circulation of these bacteria in the region in both species. Interestingly, these mycobacteria have not been identified in cattle in Atlantic Spain in such prevalences (see Table 2). In Mediterranean Spain, wild boar infection by MAC species is always lower than MTC [21,23,43]. Since these infections cause gross and histological lesions undistinguishable from TB, MAC infections must be considered when diagnosing MTC in wild boar from Atlantic habitats. As demonstrated in this study, conventional histology supplemented by immunohistochemistry to enhance specificity, would help to detect MTC in wild boar in future studies.
MTC is a multi-host pathogen modulated by host behaviour, abundance, exposure and susceptibility [4]. Whilst in Mediterranean Iberia this multi-host system is based on cattle, wild boar and red deer; in Atlantic Spain the multi-host system would include larger numbers of domestic animals (cattle, sheep and goat) and wildlife species (mainly badger and wild boar), although at lower TB prevalences. Risk factors for TB maintenance in wild boar like aggregation and high densities are not present in Atlantic Spain; but badgers are also infected in this region and could contribute to a 'mixed-species reservoir' sensu [44]; nevertheless, overall the existence of a wildlife reservoir such as in Mediterranean areas seems unlikely.

When TB lesions are observed in infected badgers, these occur often in the lungs (suggesting oro-nasal and fecal excretion) and kidneys (suggesting excretion by urine) [40]. Regarding wild boar, studies in highprevalence regions have shown high proportions of generalized TB with lung involvement, strongly suggesting oro-nasal and fecal shedding [11]. In Atlantic Spain, $0.83 \%$ and $0 \%$ infected badgers showed visible lung and kidney lesions, respectively [9]. In this study $1.43 \%$ wild boar showed visible lung lesions, therefore suggesting a higher risk of transmission.

In any case, the presence of wildlife (wild boar and badger) contributes to the risk associated with cattle TB in farms in northern Spain [Cowie CE, unpublished observations], thus the risk of infection spillback from this species to cattle cannot be excluded. As for badgers, the risk of transmission to cattle might include direct contact on pasture and in buildings, and contamination of pasture, water and cattle feed [45]. Therefore, cautionary measures to prevent contact between cattle and wild boar, and gralloch removal after hunting should be carried out. Also, wild boar population monitoring as well as wild boar TB surveillance should be continued and improved.

\section{Conclusions}

This study confirms that (a) wild boar carry MTC mycobacteria at a low prevalence in Atlantic habitats in northern Spain, probably because of climate, management and because of the main reservoir, cattle, also have a low TB prevalence, (b) wild boar from this study area present less generalized lesions than in Mediterranean Spain, possibly due to lower TB prevalence in cattle, different management, habitat and climate conditions, (c) typing reveals similar profiles to those detected in other domestic - cattle, sheep and goat - and wildlife - badger and fox - hosts in this region, suggesting epidemiological links between these species and (d) our results are relevant in the current scenario of increasing wild boar densities [37] and sympatric wildlife TB hosts in Atlantic Spain [10] and elsewhere in 
continental Europe [18,46]. To summarize, the wild boar is currently regarded as a spillover TB host in Atlantic Spain, although its status may change based on local or regional risk factors, such as an increase of cattle TB, wild boar abundance, land use changes and changes in cattle and wildlife management practices [14].

\section{Competing interests}

None of the authors of this paper has a financial or personal relationship with other people or organisations that could inappropriately influence or bias the content of the paper.

\section{Authors' contributions}

MMM, AB, NM, CG: contributed to the conception, design, and data collection, laboratory work, drafting and writing of the manuscript. LDJ, JB, $\mathrm{BR}, \mathrm{MB}, \mathrm{MFC}, \mathrm{JA}, \mathrm{SM}, \mathrm{JM}, \mathrm{JLS}$ : contributed to laboratory work, data analysis and drafting of the manuscript. All authors have read and approved the final manuscript.

\section{Acknowledgements}

The authors wish to thank the Veterinary Services of the Sección de Caza de la Consejería de Medio Ambiente del Principado de Asturias and Veterinary Services of the Consejería de Medio Rural y de Mar de la Xunta de Galicia for assistance with the sample collection. We also thank colleagues based in SERIDA, Animal Health Laboratory in Gijón, LASAPAGA-Animal Health Laboratory in Lugo and in VISAVET for their help with processing of samples. We also acknowledge the help of MAGRAMA in providing information central to our study. Dr. Kevin P. Dalton is thanked for critically reviewing the manuscript. Dr. Ana Balseiro is a recipient of a 'Contrato de Investigación para Doctores' from the Instituto Nacional de Investigación Agraria y Agroalimentaria (INIA). Nelson Marreros holds a 'fellowship for prospective researcher' from the Swiss National Science Foundation. This project was supported by INIA RTA2011-00010-00-00 (FEDER-cofinanciated) and EU FP7 grant APHAEA (EMIDA ERA-NET).

\section{Author details}

'Servicio de Sanidad Animal, Consejería de Medio Rural y de Mar, Xunta de Galicia, Edificio Administrativo San Caetano, 15781 Santiago de Compostela, A Coruña, Spain. ${ }^{2}$ SaBio-IREC (CSIC-UCLM-JCCM), Ronda de Toledo s.n., 13005 Ciudad Real, Spain. ${ }^{3}$ Departamento de Biología Molecular del Laboratorio de Sanidad y Producción Animal de Galicia, Avenida de Madrid 77, 27002 Lugo, Spain. ${ }^{4}$ VISAVET Health Surveillance Centre, Universidad Complutense, Avda, Puerta de Hierro s/n, 28040 Madrid, Spain. ${ }^{5}$ Facultad de Veterinaria (Departamento de Sanidad Animal), Universidad Complutense, Avda, Puerta de Hierro s/n, 28040 Madrid, Spain. 'Laboratorio de Sanidad Animal del Principado de Asturias, Travesía del hospital 96, 33299 Gijón, Asturias, Spain. ${ }^{7}$ Dirección General de Sanidad de la Producción Agraria MAGRAMA, 24014 Madrid, Spain. ${ }^{8}$ SERIDA, Servicio Regional de Investigación y Desarrollo Agroalimentario, Centro de Biotecnología Animal, 33394 Deva-Gijón, Asturias, Spain.

Received: 21 June 2013 Accepted: 5 September 2013

Published: 8 September 2013

\section{References}

1. Grange JM, Yates MD, Boughton E: A review. The avian tubercle bacillus and its relatives. J App/ Bacterio/ 1990, 68:411-431.

2. Gortázar C, Torres MJ, Vicente J, Acevedo P, Reglero M, de la Fuente J, Negro JJ, Aznar-Martín J: Bovine tuberculosis in Doñana biosphere reserve: the role of wild ungulates as disease reservoirs in the last Iberian lynx strongholds. PlOS ONE 2008, 3:e2776. 10.1371/journal. pone.0002776.

3. Palmer MV, Thacker TC, Waters WR, Gortázar C, Corner LAL: Mycobacterium bovis: a model pathogen at the interface of livestock, wildlife and humans. Vet Med Int 2012, 2012:236205. 10.1155/2012/236205.

4. Gortázar C, Delahay RJ, McDonald RA, Boadella M, Wilson GJ, Gavier-Widen D. Acevedo P: The status of tuberculosis in European wild mammals. Mammal Rev 2012, 42:193-206.

5. Muñoz PM, Boadella M, Arnal M, de Miguel MJ, Revilla M, Martínez D, Vicente J, Acevedo P, Oleaga A, Ruiz-Fons F, Marín CM, Prieto JM, de la
Fuente J, Barral M, Barberán M, de Luco DF, Blasco JM, Gortázar C: Spatial distribution and risk factors of Brucellosis in Iberian wild ungulates. BMC Infect Dis 2010, 10:46. 10.1186/1471-2334-10-46.

6. RASVE: Programa nacional de erradicación de tuberculosis bovina presentado por España para el año 2013; 2013. Available at: http://rasve.mapa.es/ publica/programas/NORMATIVA\%20Y\%20PROGRAMAS\%5CPROGRAMAS\% 5C2013\%5CTUBERCULOSIS\%20BOVINA\%5CPROGRAMA\%20TB\%202013.PDF.

7. McDonald RA, Delahay RJ, Carter SP, Smith GC, Cheeseman CL: Perturbing implications of wildlife ecology for disease control. Trends Ecol Evol 2008, 23:53-56.

8. Boadella M, Gortázar C, Acevedo P, Carta T, Martín-Hernando MP, de la Fuente J, Vicente J: Six recommendations for improving monitoring of diseases shared with wildlife: examples regarding mycobacterial infections in Spain. Eur J Wild Res 2011, 57:697-706.

9. Balseiro A, Rodríguez O, González-Quirós P, Merediz I, Sevilla IA, Davé D, Dalley DJ, Lesellier S, Chambers MA, Bezos J, Muñoz M, Delahay RJ, Gortázar C, Prieto JM: Infection of Eurasian badgers (Meles meles) with Mycobacterium bovis and Mycobacterium avium complex in Spain. Vet J 2011, 190:e21-e25.

10. Balseiro A, González-Quirós P, Rodríguez O, Copano MF, Merediz I, de Juan L, Chambers MA, Delahay RJ, Marreros N, Royo L, Bezos J, Prieto JM, Gortázar C: Spatial relationships between Eurasian badgers (Meles meles) and cattle infected with Mycobacterium bovis in Northern Spain. Vet $J$ 2013. 10.1016/j.tvjl.2013.03.017.

11. Martín-Hernando MP, Höfle U, Vicente J, Ruiz-Fons F, Vidal D, Barral M, Garrido JM, de la Fuente J, Gortázar C: Lesions associated with Mycobacterium tuberculosis complex infection in the European wild boar. Tuberculosis 2007, 87:360-367.

12. Naranjo V, Gortázar C, Vicente J, de la Fuente J: Evidence of the role of European wild boar as a reservoir of Mycobacterium tuberculosis complex. Vet Microbiol 2008, 127:1-9.

13. Boadella M, Lyashchenko K, Greenwald R, Esfandiari J, Jaroso R, Carta T, Garrido JM, Vicente J, de la Fuente J, Gortázar C: Serologic tests for detecting antibodies against Mycobacterium bovis and Mycobacterium avium subspecies paratuberculosis in Eurasian wild boar (Sus scrofa scrofa). J Vet Diagn Invest 2011, 23:77-83.

14. Gortázar C, Vicente J, Boadella M, Ballesteros C, Galindo RC, Aranaz A, de la Fuente J: Progress in the control of bovine tuberculosis in Spanish wildlife. Vet Microbiol 2011, 151:170-178.

15. Santos N, Correia-Neves M, Ghebremichael S, Källenius G, Svenson SB, Almeida V: Epidemiology of Mycobacterium bovis infection in wild boar (Sus scrofa) in Portugal. J Wild Dis 2009, 45:1048-1061.

16. Zanella G, Durand B, Hars J, Moutou F, Garin-Bastuji B, Duvauchelle A, Fermé M, Karoui C, Boschiroli ML: Mycobacterium bovis in wildlife in France. J Wild Dis 2008, 44:99-108.

17. Dondo A, Zoppi S, Rossi F, Chiavacci L, Barbaro A, Garonne A, Benedetto A, Gloria M: Mycobacteriosis in wild boar: results of 2000-2006 activity in Northern Italy. Epid San Anim 2007, 51:35-42.

18. Schöning JM, Cerny N, Prohaska S, Wittenbrink MM, Smith NH, Bloemberg G, Pewsner M, Schiller I, Origgi FC, Ryser-Degiorgis MP: Surveillance of bovine tuberculosis and risk estimation of a future reservoir formation in wildlife in Switzerland and Liechtenstein. PloS ONE 2013, 8:e54253. 10.1371/journal.pone.0054253.

19. Boadella M, Acevedo P, Vicente J, Mentaberre G, Balseiro A, Arnal M, Martínez D, García-Bocanegra I, Casal C, Alvarez J, Oleaga A, Lavín S, Muñoz M, Sáez-Llorente JL, de la Fuente J, Gortázar C: Spatio-temporal trends of Iberian wild boar contact with Mycobacterium tuberculosis complex detected by ELISA. Ecohealth 2011. 10.1007/s10393-011-0713-y.

20. Domingos M, Amado A, Botelho A: IS1245 RFLP analysis of strains of Mycobacterium avium subspecies hominissuis isolated from pigs with tuberculosis lymphadenitis in Portugal. Vet Rec 2009, 164:116-120.

21. Parra A: Epidemiología de la tuberculosis en artiodáctilos salvajes en Extremadura, PhD Thesis. University of Extremadura; 2003.

22. Zanetti S, Bua A, Molicotti P, Delogu G, Mura A, Ortu S, Sechi LA: Identification of mycobacterial infections in wild boar in Northern Sardinia, Italy. Acta Vet Hung 2008, 56:145-152.

23. García-Jiménez WL, Benítez-Medina JM, Martínez R, Carranza J, Cerrato R, García-Sánchez A, Risco D, Moreno JC, Sequeda M, Gómez L, FernándezLlario P, Hermoso De Mendoza J: Non-tuberculous mycobacteria in wild boar (Sus scrofa) from Southern-Spain: Epidemiological, clinical and diagnostic concerns. Transbound Emerg Dis 2013. 10.1111/tbed.12083. 
24. Rodríguez-Campos S, González S, de Juan L, Romero B, Bezos J, Casal C, Álvarez J, Fernández-de-Mera IG, Castellanos E, Mateos A, Sáez-Llorente JL, Domínguez L, Aranaz A, Spanish Network on Surveillance Monitoring of Animal Tuberculosis: The Spanish network on surveillance and monitoring of animal tuberculosis. A database for animal tuberculosis (mycoDB.es) within the context of the Spanish national programme for eradication of bovine tuberculosis. Infect Genet Evol 2012, 12:877-882.

25. Coletsos PJ: Media and methods of culture suitable for the reanimation and multiplication in vitro of Mycobacterium tuberculosis of reduced vitality, of ephemeral viability, or in a state of quiescence. Ann I Pasteur Paris 1960, 99:475-495.

26. Idigoras $P$, Beristain $X$, Iturzaeta A, Vicente D, Pérez-Trallero E: Comparison of the automated nonradiometric Bactec MGIT 960 system with Löwenstein-Jensen, Coletsos, and Middlebrook $7 \mathrm{H} 11$ solid media for recovery of mycobacteria. Eur J Clin Microbiol Infect Dis 2000, 19:350-354.

27. Coetsier C, Vannuffel P, Bloondel N, Denef JF, Cocito C, Gala JL: Duplex PCR for differential identification of Mycobacterium bovis, M. avium, and $M$. avium subsp. paratuberculosis in formalin-fixed paraffin-embedded tissues from cattle. J Clin Microbiol 2000, 38:3048-3054

28. Kamerbeek J, Schouls L, Kolk A, Van Agterveld M, Van Soolingen D, Kuijper S, Bunschoten A, Molhuizen H, Shaw R, Goyal M, Van Embden J: Simultaneous detection and strain differentiation of Mycobacterium tuberculosis for diagnosis and epidemiology. J Clin Microbiol 1997, 35:907-914.

29. Smith N, Upton P: Naming spoligotype patterns for the RD9-deleted lineage of the Mycobacterium tuberculosis complex. Infect Genet Evol 2012, 12:873-876. www.mbovis.org

30. Rodríguez-Campos S, Aranaz A, de Juan L, Sáez-Llorente JL, Romero B, Bezos J, Jiménez A, Mateos A, Domínguez L: Limitations of spoligotyping and variable number tandem repeat typing for molecular tracing of Mycobacterium bovis in a high diversity setting. J Clin Microbiol 2011, 49:3361-3364.

31. Balseiro A, Merediz I, Sevilla IA, García-Castro C, Gortázar C, Prieto JM, Delahay RJ: Infection of Eurasian badgers (Meles meles) with Mycobacterium avium complex (MAC) bacteria. Vet J 2011, 188:231-233.

32. Gortázar C, Vicente J, Gavier-Widén D: Pathology of bovine tuberculosis in the European wild boar (Sus scrofa). Vet Rec 2003, 152:779-780.

33. Sternberger LA, Hardy PH, Cuculis JJ, Meyer HG: The unlabeled antibody enzyme method of immunohistochemistry: preparation and properties of soluble antigen antibody complex (horseradish peroxidaseantihorseradish peroxidase) and its use in identification of spirochetes. J Histochem Cytochem 1970, 18:315-333.

34. R development core team: $R$ : A Language and Environment for Statistical Computing. Vienna, Austria: R Foundation for Statistical Computing; 2012 http://www.R-project.org

35. Meyer D, Zeileis A, Hornik K: Vcd: Visualizing Categorical Data.; 2012. R package version 1.2-13. Available at: http://cran.r-project.org/web/packages/ vcd/vcd.pdf.

36. Vieira-Pinto M, Alberto J, Aranha J, Serejo J, Canto A, Cuhna MV, Botelho A: Combined evaluation of bovine tuberculosis in wild boar (Sus scrofa) and red deer (Cervus elaphus) in central-east Portugal. Eur J Wild Res 2011, 57:1189-1202.

37. Acevedo P, Vicente J, Ruiz-Fons JF, Cassinello J, Gortázar C: Estimation of European wild boar relative abundance and aggregation: a novel method in epidemiological risk assessment. Epidemiol Infect 2007 135:519-527.

38. González-Quirós P, Baldó L, Alvarez G, Fernández-Villasuso A: La Caza como Recurso Turístico en la Montaña Central de Asturias. Report for the Government of Asturias. Leader Consorcio Montaña Central de Asturias; 2012

39. Vicente J, Höfle U, Garrido JM, de Fernández de Mera IG, Acevedo P, Juste R, Barral M, Gortázar C: Risk factors associated with the prevalence of tuberculosis-like lesions in fenced wild boar and red deer in south central Spain. Vet Res 2007, 38:451-464

40. Crawshaw TR, Griffiths IB, Clifton-Hadley RS: Comparison of a standard and a detailed postmortem protocol for detecting Mycobacterium bovis in badgers. Vet Rec 2008, 163:473-477.

41. Arenas-Montes A, García-Bocanegra I, Paniagua J, Franco JJ, Miró F, Fernández-Morente M, Carbonero A, Arenas A: Blood sampling by puncture in the cavernous sinus from hunted wild boar. Eur J Wild Res 2013, 59:299-303.

42. Woodroffe R, Donnelly CA, Johnston WT, Bourne FJ, Cheeseman CL, CliftonHadley RS, Cox DR, Gettinby G, Hewinson RG, Le Fevre AM, Mclnerney JP,
Morrison WI: Spatial association of Mycobacterium bovis infection in cattle and badgers (Meles meles). J Appl Ecol 2005, 42:852-862

43. Gortázar C, Torres MJ, Acevedo P, Aznar J, Negro JJ, de la Fuente J, Vicente $\mathrm{J}$ : Fine-tuning the space, time and host distribution of mycobacteria in wildlife. BMC Microbio/ 2011, 11:27. 10.1186/1471-2180-11-27.

44. Haydon DT, Cleaveland S, Taylor LH, Laurenson MK: Identifying reservoirs of infection: a conceptual and practical challenge. Emerg Infect Dis 2002, 8:1468-1473.

45. Bourne FJ, Donelly C, Cox D, Gettinby G, Mclnerney JP, Morrison I, Woodroffre R: Bovine TB: The scientific evidence, a science base for a sustainable policy control TB in cattle, an epidemiological investigation into bovine tuberculosis, Final report of the Independent Scientific Group on Cattle TB. London, UK: Department for Environment, Food and Rural Affairs (DEFRA); 2007

46. Payne A, Boschiroli ML, Gueneau E, Moyen JLK, Rambaud T, Dufour B, GilotFromont $\mathrm{E}$, Hars J: Bovine tuberculosis in Eurasian badgers (Meles meles) in France. Eur J Wild Res 2013. 10.1007/s10344-012-0678-3.

doi:10.1186/1746-6148-9-176

Cite this article as: Muñoz-Mendoza et al:: Wild boar tuberculosis in Iberian Atlantic Spain: a different picture from Mediterranean habitats. BMC Veterinary Research 2013 9:176.

\section{Submit your next manuscript to BioMed Central and take full advantage of:}

- Convenient online submission

- Thorough peer review

- No space constraints or color figure charges

- Immediate publication on acceptance

- Inclusion in PubMed, CAS, Scopus and Google Scholar

- Research which is freely available for redistribution

Submit your manuscript at www.biomedcentral.com/submit
C Biomed Central 